\title{
Surgical Management of Skeletal Class II Deformity Patients- a Case Series
}

\author{
Mehta Payal ${ }^{1,}$,, Nimisha Desai ${ }^{1}$, Nehal Patel ${ }^{2}$, Tushar Makwana ${ }^{1}$ \\ ${ }^{1}$ Department of Oral and Maxillofacial Surgery, Karnavati School of Dentistry, Gandhinagar, India \\ ${ }^{2}$ Fellowship in Cleft and TMJ, ABMSS Cleft Center, Surat, India \\ Email address: \\ mehtapayal199326@gmail.com (M. Payal) \\ ${ }^{*}$ Corresponding author
}

\section{To cite this article:}

Mehta Payal, Nimisha Desai, Nehal Patel, Tushar Makwana. Surgical Management of Skeletal Class II Deformity Patients- a Case Series International Journal of Clinical Oral and Maxillofacial Surgery. Vol. 6, No. 2, 2020, pp. 49-55. doi: 10.11648/j.ijcoms.20200602.16

Received: October 20, 2020; Accepted: November 6, 2020; Published: December 8, 2020

\begin{abstract}
Class II malocclusions constitute a high percentage of ortho-surgically treated cases. Approximately $70 \%$ of the patients have associated skeletal discrepancy characterized by an exaggerated sagittal distance between the maxilla and the mandible, which could result in maxillary prognathism, mandibular retrognathism, or both (2) Class II malocclusion can be treated by a combination of maxillary and mandibular surgeries, maxillary surgery alone or by mandible surgery solely depending on the underlying skeletal discrepancy i.e Maxillary Le Fort I superior repositioning with autorotation of mandible, Bi-jaw surgery_-bilateral sagittal split osteotomy (BSSO) along with maxillary Le Fort I impaction., Genioplasty-advancement of chin. Material and methods: 10 cases of Skeletal Class -II malocclusion were selected randomly irrespective of age, sex, caste, religion, etiology and socioeconomic status, good general health without any systemic disease. Study was conducted in the Department of Oral and Maxillofacial Surgery, Karnavati School of Dentistry, Uvarsad. Conclusion: 14 According to the outcomes of the cases it provided a reliable esthetic and functional enhancement of the patient when maxilla was superiorly positioned, with mandibular advancement, genioplasty for retruded chin according to the treatment planned for each patient.
\end{abstract}

Keywords: Skeletal Class II, Deformity, Orthognathic Surgery, Surgical Management

\section{Introduction}

Class II malocclusions constitute a high percentage of ortho-surgically treated cases [4], Approximately $70 \%$ of the patients have associated skeletal discrepancy characterized by an exaggerated sagittal distance between the maxilla and the mandible, which could result in maxillary prognathism, mandibular retrognathism, or both [2]. Class II malocclusion can be treated by a combination of maxillary and mandibular surgeries, maxillary surgery alone or by mandible surgery solely depending on the underlying skeletal discrepancy i.e Maxillary Le Fort I superior repositioning with autorotation of mandible, Bi-jaw surgery-bilateral sagittal split osteotomy (BSSO) along with maxillary Le Fort I impaction., Genioplasty-advancement of chin. When there are severe skeletal components also associated with that malocclusion, such as a vertical growth pattern and a retruded mandible, a combined surgical approach is often the best treatment option [5]. Treatment choices for preadolescents and teenagers are particularly difficult because of the uncertainty regarding the magnitude and direction of remaining growth. The results obtained by surgical management of such cases usually ensure a better esthetic, functional stability [1]. The goal of orthognathic surgery is basically to achieve harmony between functional stability and esthetic enhancement $[3,6,7]$ which thereby fulfils patients need. So here in this study we have evaluated result of 10 patients of skeletal class II deformity treated surgically and their outcomes we have discussed.

\section{Aims and Objectives}

The aim of the study was to surgically correct with either Bilateral sagittal split osteotomy, Lefort I osteotomy, genioplasty or Bijaw surgery as indicated in skeletal class II deformity patients. The objective of this study was: To study different cases of skeletal class II malocclusion, to surgically correct facial asymmetry, to achieve stable occlusion, to achieve satisfactory esthetics and function. 


\section{Materials and Methods}

\subsection{Methods of Data Collection}

\section{Definition of Study Subject}

10 cases of Skeletal Class -II malocclusion were selected randomly irrespective of age, sex, caste, religion, etiology and socioeconomic status, good general health without any systemic disease. Study was conducted in the Department of Oral and Maxillofacial Surgery, Karnavati School of Dentistry, Uvarsad for evaluation of different treatment modalities such as Maxillary Le Fort I superior repositioning with autorotation of mandible, Bi-jaw surgery-bilateral sagittal split osteotomy (BSSO) along with maxillary Le Fort I impaction., Genioplasty - advancement of chin for surgical management of skeletal Class-II deformity.

It is a retrospective human study and ethical committe and all authors have got institutional review board approval.

\subsection{Method (Study Design)}

According to each patient requirement different osteotomy procedures were carried outfor 10 different patients. They were as follows: as Maxillary Le Fort I superior repositioning with autorotation of mandible, Bi-jaw surgery - Bilateral sagittal split osteotomy (BSSO) along with maxillary Le Fort I impaction., Genioplasty - advancement of chin for surgical management of skeletal Class-II deformity.

\section{Discussion}

Deformities at an early age, when the patient is still growing, have the potential to be corrected with growthmodifying appliances. But in adults Class II malocclusion, surgical intervention to reposition the jaws and dentoalveolar segments becomes the only option to treat such patients where growth modulation is not possible using fixed functional appliances (FFA), headgear, camouflage to mask the underlying skeletal discrepancy [10]. This cases can be treated by a combination of maxillary and mandibular surgeries, maxillary surgery alone or by mandible surgery solely depending on the underlying skeletal disepancyMaxillary Le Fort I (superior repositioning) with autorotation of mandible, Bi-jaw surgery-bilateral sagittal split osteotomy (BSSO) along with maxillary Le Fort I superior positioning., Genioplasty_advancement of chin. The results obtained by surgical as well as orthodontic management of such cases usually ensure a better esthetic, functional stability.

10 patients of skeletal class II have been treated surgically and results evaluated were: Out of 10 cases 3 patients underwent Bijaw surgery. And 7 patients underwent Single jaw surgery. In the cases of vertical maxillary excess cases single jaw surgery was planned in most of the cases. "Careful diagnosis and treatment planning is required for successful outcome of any Skeletal class II patient-Hanumath et al [8]. It is Sometimes difficult to improve labially inclined teeth, particularly in patients with mandibular retrognathia, because symphysis menti is often thin. Insufficient space therefore is available to permit sagittal rotation of the teeth without root exposure from the alveolar bone. And so 3 staged method for correction of skeletal discrepancy is advised (Kazuhiro Matsushita). Genioplasty for retruded chin and constructing infrastructure for subsequent le fort 1 osteotomy and then lefort 1 osteotomy itself is carried, finally a two-jaw surgery.

\section{Conclusion}

Overall Class II malocclusions require careful diagnosis and treatment planning for a successful outcome [12]. Treatment planning according to the level of discrepancy ensures stability and good outcome $[8,9]$. Orthodontics play a crucial role in management and patient satisfaction. Surgical superior repositioning of the maxilla for aesthetic and functional correction of selected dentofacial deformities, especially open bite deformity, produces an optimum aesthetic correction of the deformity with excellent stability [13]. Mandibular sagittal split osteotomy in combination with pre- and postsurgical orthodontics is an efficient approach in the therapy of adult Class II, division 1 malocclusion. Sagittal occlusal malrelationships are corrected and the hardand soft tissue profiles straightened in a consistent way [14]. According to the outcomes of the cases it provided a reliable esthetic and functional enhancement of the patient when maxilla was superiorly positioned, with mandibular advancement, genioplasty for retruded chin according to the treatment planned for each patient.

Result: the different surgeries done in 10 different patients accordingly are summarised in Table 1.

Table 1. Data of 10 Patients with Skeletal Class II Patients which Were Surgically Managed by Different Orthognathic Surgery.

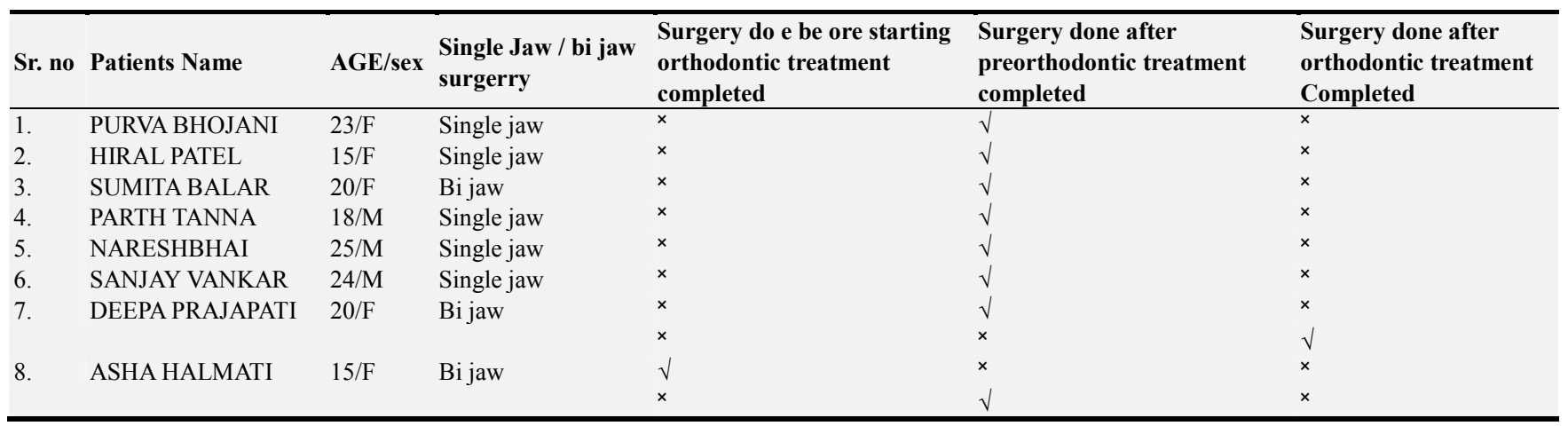




\begin{tabular}{|c|c|c|c|c|c|c|}
\hline Sr. no & Patients Name & AGE/sex & $\begin{array}{l}\text { Single Jaw / bi jaw } \\
\text { surgerry }\end{array}$ & $\begin{array}{l}\text { Surgery do e be ore starting } \\
\text { orthodontic treatment } \\
\text { completed }\end{array}$ & $\begin{array}{l}\text { Surgery done after } \\
\text { preorthodontic treatment } \\
\text { completed }\end{array}$ & $\begin{array}{l}\text { Surgery done after } \\
\text { orthodontic treatment } \\
\text { Completed }\end{array}$ \\
\hline 9. & MIRALI RIBADIYA & $16 / \mathrm{F}$ & Bi jaw & $x$ & $\sqrt{ }$ & $x$ \\
\hline 10. & SONIYA & $20 / \mathrm{F}$ & Single jaw & $\times$ & $\sqrt{ }$ & $x$ \\
\hline
\end{tabular}

Table 1. Continued.

\begin{tabular}{|c|c|c|c|c|}
\hline Sr. no & Patients Name & Osteotomy performed & Treatment done & $\begin{array}{l}\text { Advancement /rotation/superior positioning } \\
\text { performed }\end{array}$ \\
\hline 1. & PURVA BHOJANI & Mandibular Osteotomy & bilateral sagittal split osteotomy & $\begin{array}{l}\text { Advancement of } 4 \mathrm{~mm} \text { on RIGHT SIDE And } 7 \mathrm{~mm} \\
\text { on LEFT SIDE of mandible }\end{array}$ \\
\hline 2. & HIRAL PATEL & Mandibular Osteotomy & bilateral sagittal split osteotomy & $\begin{array}{l}\text { Advancement of } 6 \mathrm{~mm} \text { on RIGHT SIDE And } 8 \mathrm{~mm} \\
\text { on LEFT SIDE of mandible }\end{array}$ \\
\hline 3. & SUMITA BALAR & $\begin{array}{l}\text { Maxillary and mandibular } \\
\text { osteotomy }\end{array}$ & $\begin{array}{l}\text { lefort i osteotomy right side } \\
\text { bilateral sagittal split osteotomy }\end{array}$ & $\begin{array}{l}\text { Advancement of } 4 \mathrm{~mm} \text { on RIGHT SIDE of } \\
\text { mandible }\end{array}$ \\
\hline 4. & PARTH TANNA & Maxillary osteotomy & lefort i osteotomy & $\begin{array}{l}\text { Superior positioning of maxilla i.e anteriorly } 6 \mathrm{~mm} \\
\text { and posteriorrly } 5 \mathrm{~mm}\end{array}$ \\
\hline 5. & NARESHBHAI & Mandibular Osteotomy & bilateral sagittal split osteotomy & $\begin{array}{l}\text { Advancement of } 6 \mathrm{~mm} \text { on RIGHT SIDE And } 7 \mathrm{~mm} \\
\text { on LEFT SIDE of mandible }\end{array}$ \\
\hline 6. & SANJAY VANKAR & Maxillary osteotomy & lefort i osteotomy & $\begin{array}{l}\text { Superior positioning of maxilla i.e anteriorly } 6 \mathrm{~mm} \\
\text { and posteriorrly } 4 \mathrm{~mm}\end{array}$ \\
\hline 7. & DEEPA PRAJAPATI & \multirow{4}{*}{$\begin{array}{l}\text { Maxillary osteotomy } \\
\text { genioplasty } \\
\text { Mandibular osteotomy } \\
\text { lefort i segmental } \\
\text { osteotomy }\end{array}$} & lefort i segmental osteotomy & Anterior maxillary setback \\
\hline \multicolumn{2}{|c|}{ Mandibular osteotomy } & & Advancement of mandible was done & \\
\hline 8. & ASHA HALMATI & & genioplasty & Advancement of mandible \\
\hline \multicolumn{2}{|c|}{ Maxillary osteotomy } & & Anterior maxillary setback & \\
\hline \multirow[t]{2}{*}{9.} & \multirow[t]{2}{*}{ MIRALI RIBADIYA } & Maxillary osteotomy & lefort i osteotomy & Superior positioning of maxilla \\
\hline & & Mandibular osteotomy & $\begin{array}{l}\text { bilateral sagittal split osteotomy } \\
\text { genioplasty }\end{array}$ & Advancement of mandible \\
\hline 10. & SONIYA & Maxillary osteotomy & lefort i osteotomy & $\begin{array}{l}\text { Superior positioning of maxilla i.e anteriorly } 5 \mathrm{~mm} \\
\text { and posteriorrly } 3 \mathrm{~mm}\end{array}$ \\
\hline
\end{tabular}

Case-1

Name- Poorva

Age - 23/F

Single/Bijaw - Single jaw surgery.

Treatment Done- BILATERAL SAGITTAL SPLIT OSTEOTOMY.

(Advancement of $4 \mathrm{~mm}$ on RIGHT SIDE And $7 \mathrm{~mm}$ on LEFT SIDE of mandible.)

Preoperative Photographs.
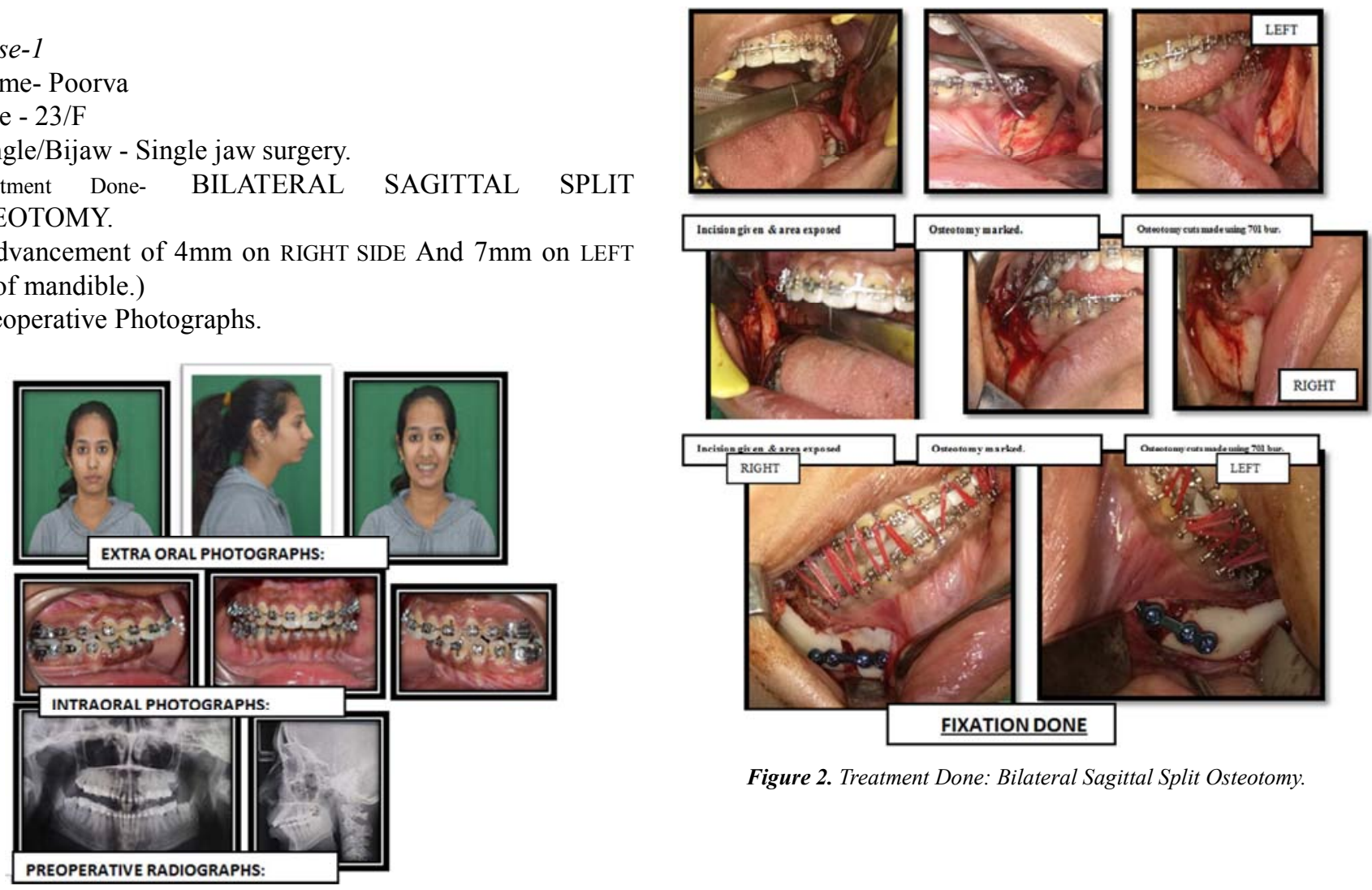

Figure 2. Treatment Done: Bilateral Sagittal Split Osteotomy.

Figure 1. Extraoral photograph-front view lateral view; intraoral photographs, preoperative radiograph-OPG, Lateral cephalogram. 

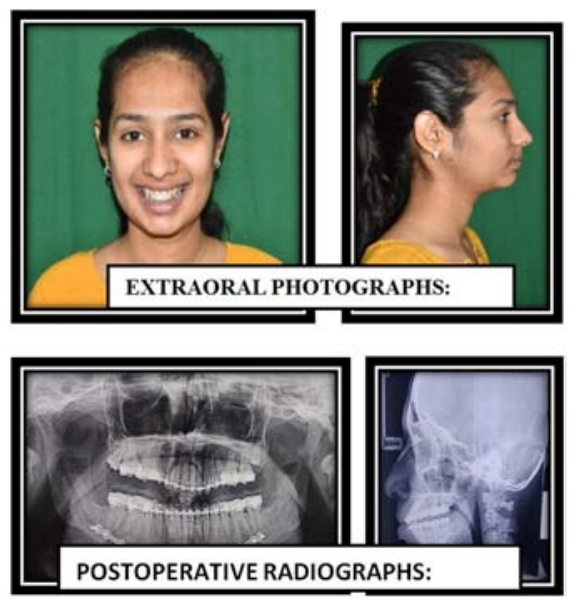

Figure 3. Postoperative records.

Case-2

Name- HIRAL

Age - $15 / \mathrm{F}$

Single/Bijaw - Single jaw surgery.

Treatment Done- BILATERAL SAGITTAL SPLIT OSTEOTOMY.

(Advancement of $6 \mathrm{~mm}$ on RIGHT SIDE And $8 \mathrm{~mm}$ on LEFT SIDE of mandible.)

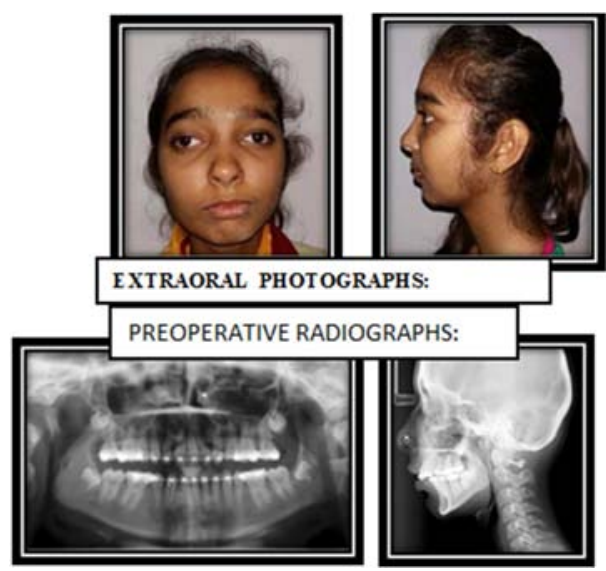

Figure 4. Preoperative records.
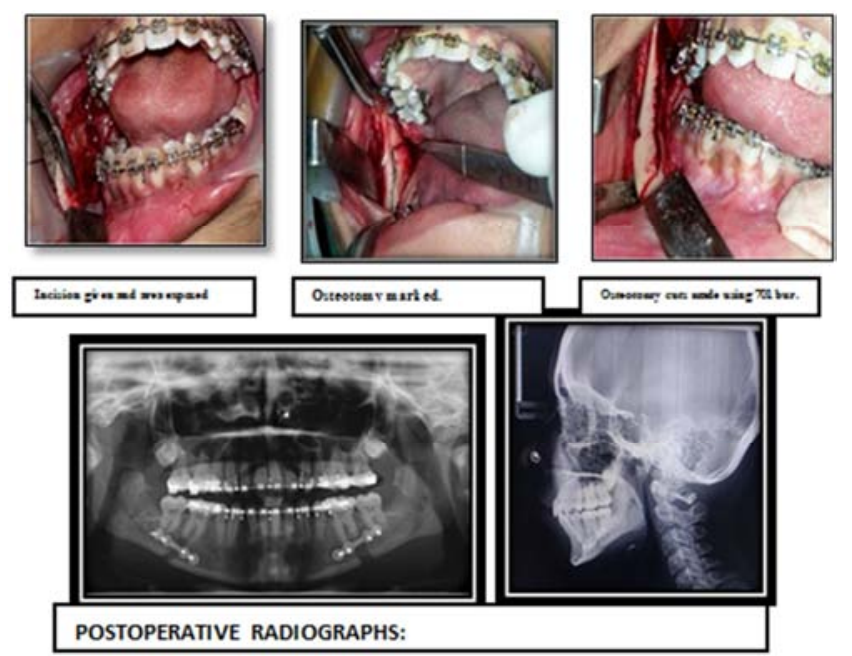

Figure 5. Treatment done.
Case-3

Name- SUMITA

Age - 20/F

Single/Bijaw - Bi jaw surgery.

Treatment Done- LEFORT I OSTEOTOMY

RIGHT SIDE BILATERAL SAGITTAL SPLIT OSTEOTOMY

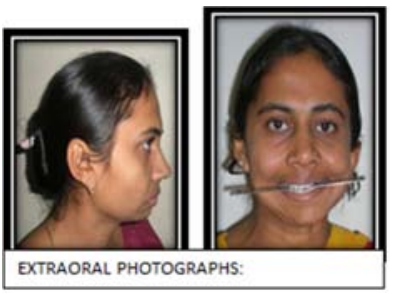

Figure 6. Preoperative records.
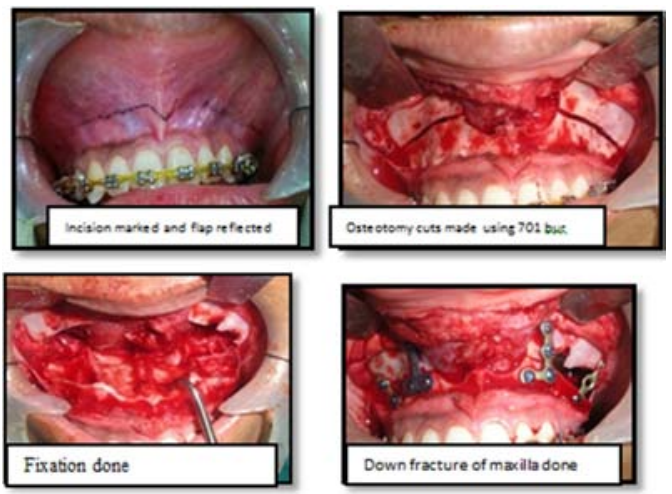

Figure 7. Treatment done: lefort I osteotomy
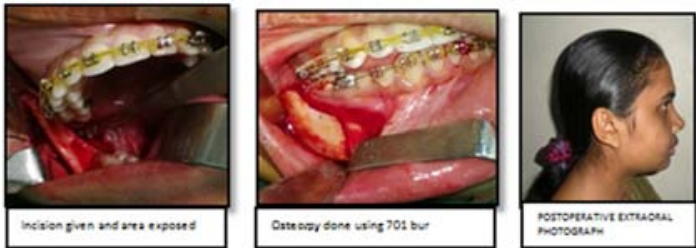

Figure 8. Bilateral sagittal split osteotomy.

Case-4

Name- PARTH

Age - 18/M

Single/Bijaw - Single jaw surgery.

Treatment Done- LEFORT I OSTEOTOMY

PREOPERATIVE RECORDS:

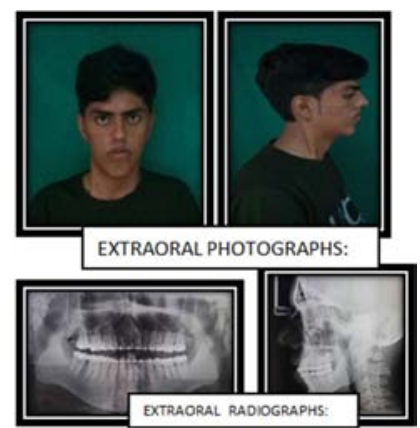

Figure 9. Preoperative photographs. 

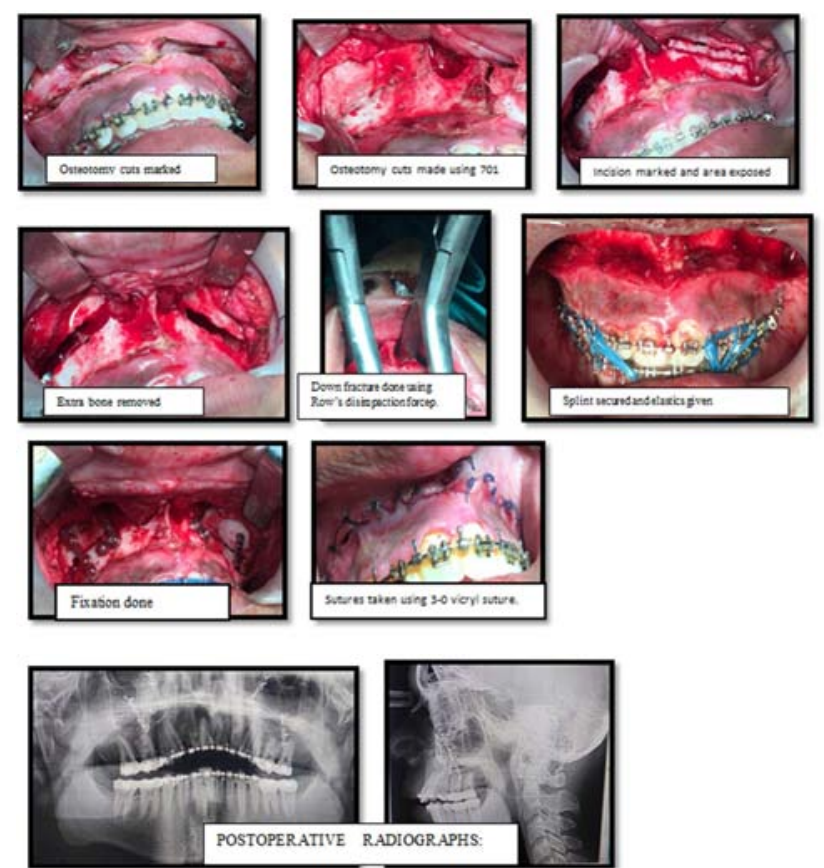

Figure 10. Treatment done: lefort i osteotomy.

Case-7

Name- Deepa

Age - 20/F

Single/Bijaw - Bi jaw surgery.

Treatment Done-1. LEFORT I SEGMENTAL OSTEOTOMY, 2. GENIOPLASTY
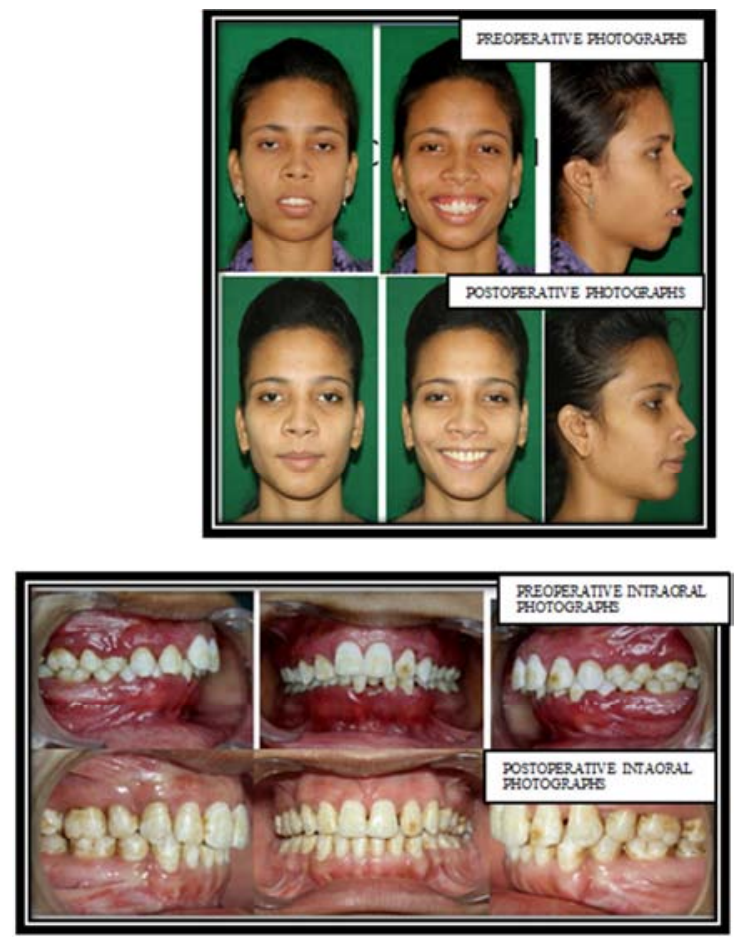

Figure 11. Preoperative record.
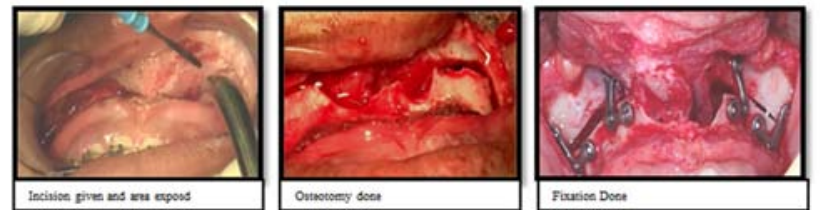

Figure 12. Treatment done: lefort i osteotomy
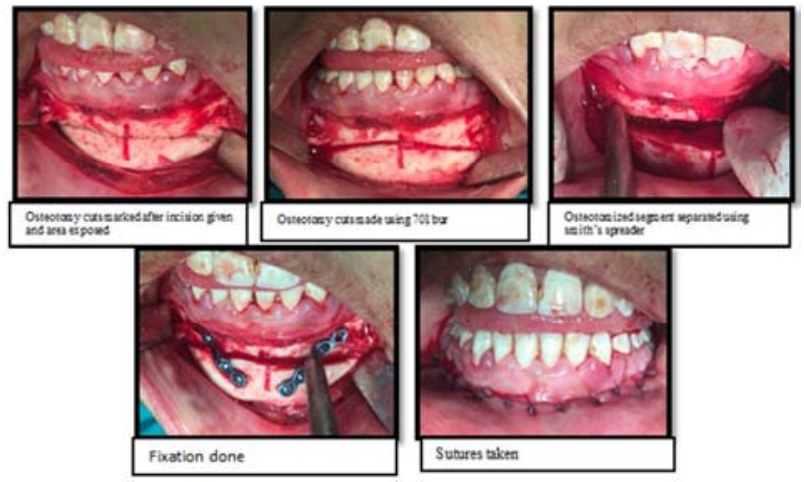

Figure 13. Genioplasty.
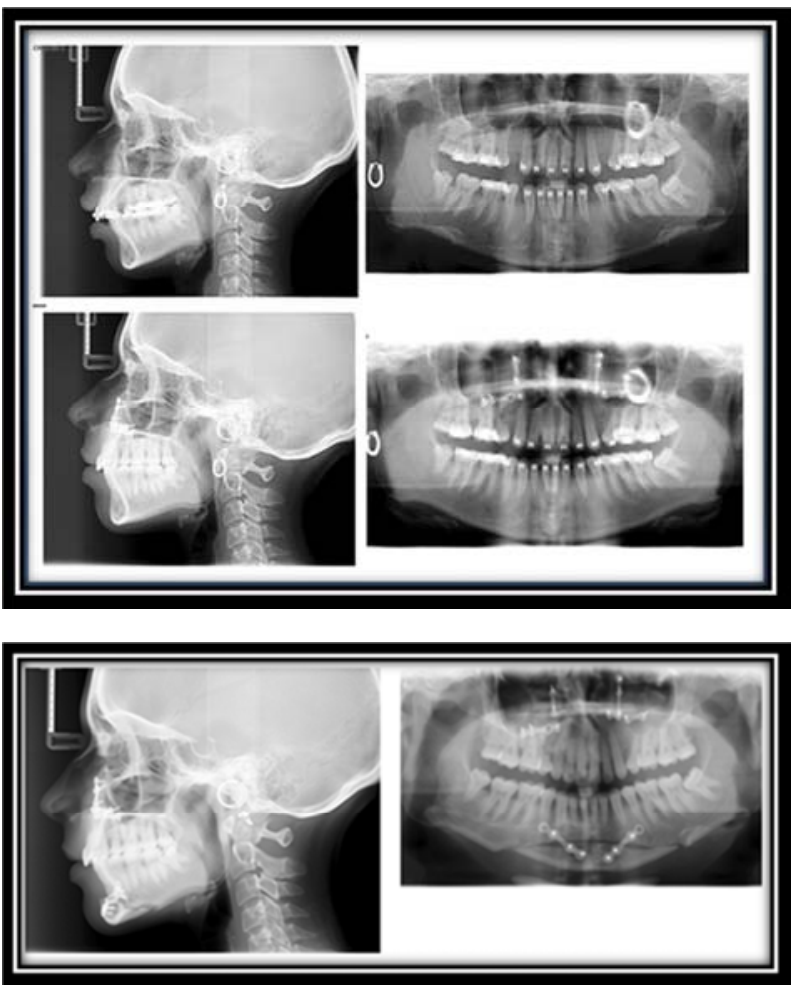

Figure 14. Radiographs.

Case-8

Name- MIRALI

Age - 16/F

Single/Bijaw - Single jaw surgery.

Treatment Done- 1. LEFORT I OSTEOTOMY

2. BILATERAL SAGITTAL SPLIT OSTEOTOMY.

3. GENIOPLASTY 


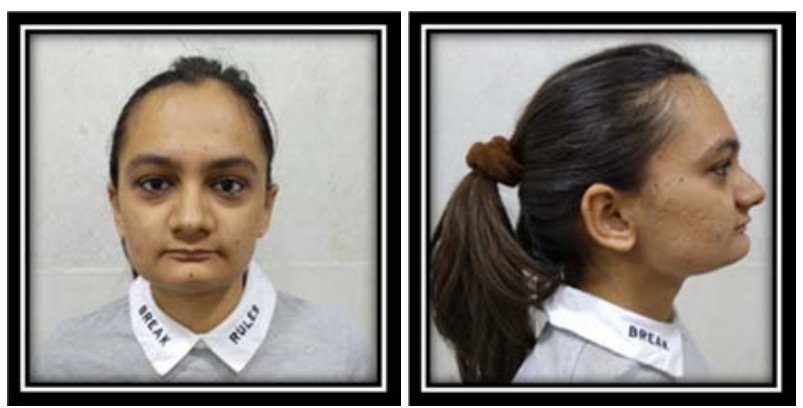

Figure 15. Preoperative records.
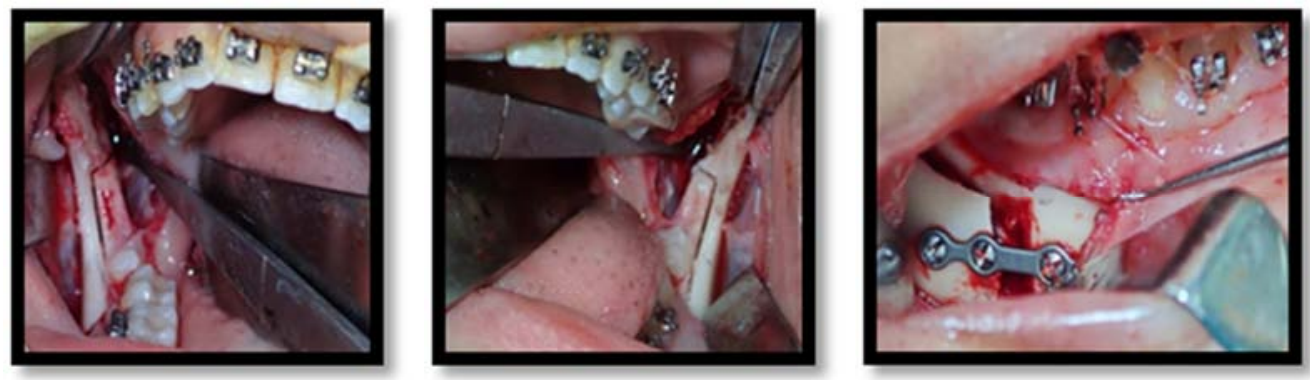

Figure 16. Bilateral sagittal split osteotomy.
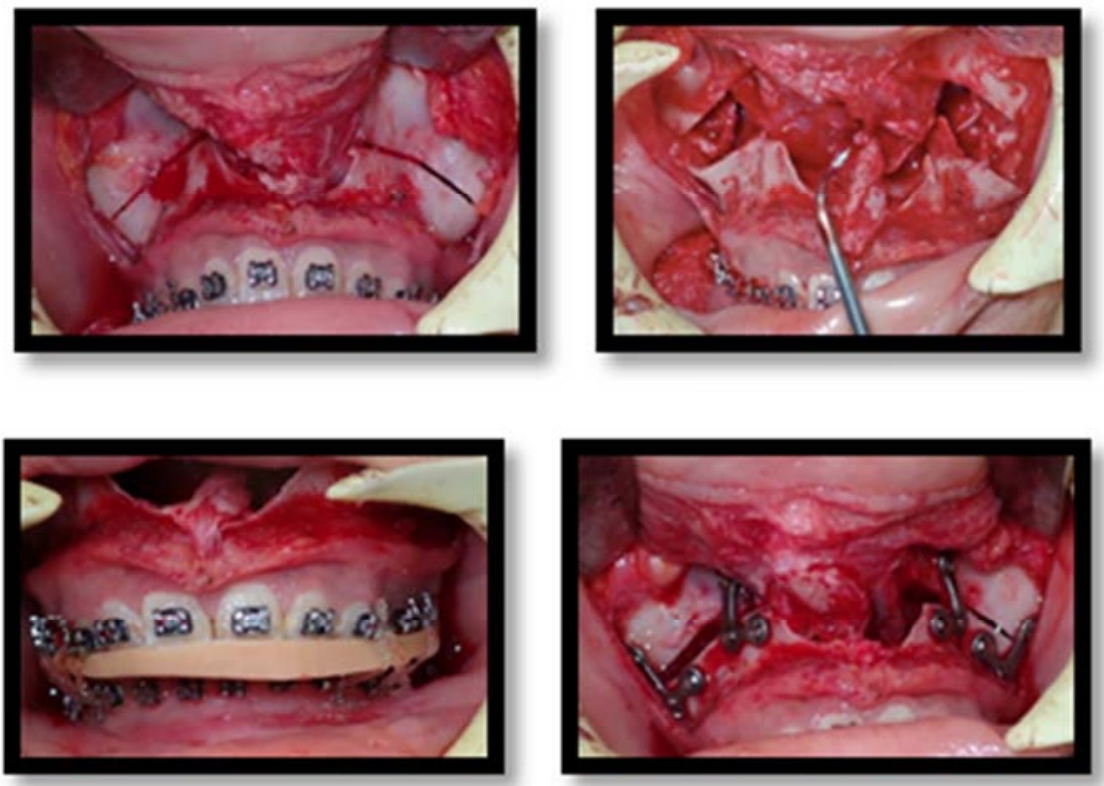

Figure 17. Lefort I osteotomy.
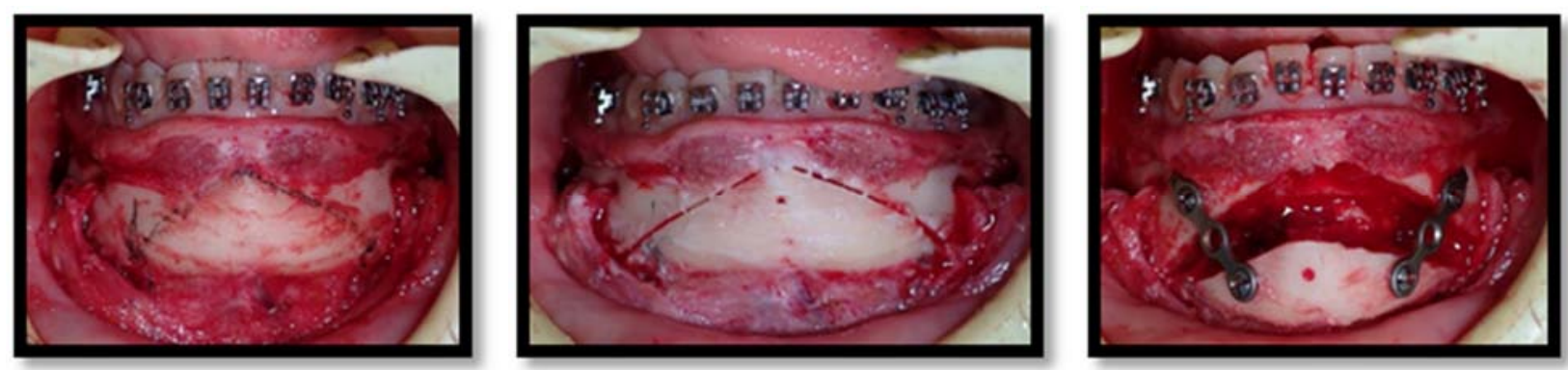

Figure 18. Genioplasty. 


\section{References}

[1] Sundararajan S, Parameswaran R, Vijayalakshmi D. Orthognathic surgical approach for management of skeletal class II vertical malocclusion. Contemp Clin Dent. 2018 Jun 1; $9(5)$.

[2] Donjuán Villanueva JJ, Vásquez Estrada HA, Hernández Carvallo JR, Nachón García MG. Surgical-orthodontic treatment in a class II malocclusion patient. Case report. Rev Mex Ortod. 2016.

[3] Gupta H, Autar R, Abraham J, Bagchi P, Gupta S. Combined orthodontic and surgical correction of adult skeletal class II with hyperdivergent jaws. Natl J Maxillofac Surg. 2012; 3 (1): 6.

[4] Sarnat BG. Effects and noneffects of personal environmental experimentation on postnatal craniofacial growth. J Craniofac Surg. 2001; 12 (3): 205-1.

[5] Janson M, Janson G, Sant'Ana E, Simão TM, De Freitas MR. An orthodontic-surgical approach to class II subdivision malocclusion treatment. J Appl Oral Sci. 2009; 17 (3): 266-7.

[6] Forssell K, Turvey TA, Phillips C, Proffit WR. Superior repositioning of the maxilla combined with mandibular advancement: Mandibular RIF improves stability. Am J Orthod Dentofac Orthop. 1992; 102 (4): 342-5.

[7] Matsushita K, Yamaguchi HO, Koshikawa-Matsuno M, Inoue
N. Evaluation of a three-stage method for improving mandibular retrognathia with labially inclined incisors using genioplasty, segmental osteotomy, and two-jaw surgery. Case Rep Med. 2014; 201.

[8] Krishna Nayak US. Surgical Orthodontic treatment of Skeletal Class II malocclusion. Vol. 3, Journal of Scientific Dentistry.

[9] Katta A, Rajasigamani K, Balachander R, Karthik K. Surgical correction of class II skeletal malocclusion in an adult patient. J Orofac Sci [Internet]. 2014 [cited 2019 Dec 5]; 6 (1): 5 Available from: http://www.jofs.in/text.asp?2014/6/1/58/132587.

[10] Chhibber A, Upadhyay M, Uribe F, Nanda R. Long-term surgical versus functional Class II correction: A comparison of identical twins. Angle Orthod. 2015 Jan 1; 85 (1): 142-5.

[11] Daokar ST, Agrawal G, Chaudhari C, Yamyar S. Orthosurgical Management of Severe Skeletal Class II Div 2 Malocclusion in Adult. Orthod J Nepal. 2018 Jan 7; 7 (1): 44 5.

[12] Wertz RA. Diagnosis and treatment planning of unilateral class II malocclusions. Angle Orthod. 1975; 45 (2): 85-9.

[13] Schendel SA, Eisenfeld JH, Bell WH, Epker BN. Superior repositioning of the maxilla: Stability and soft tissue osseous relations. Am J Orthod. 1976; 70 (6): 663-7.

[14] Epker BN, Fish LC. Surgical superior repositioning of the maxilla: What to do with the mandible? Am J Orthod. 1980; 78 (2): 164-9. 